\title{
Hydrodynamics of a Novel Design Circulating Fluidized Bed Steam Reformer Operating in the Dense Suspension Upflow Regime
}

\author{
Moataz Bellah M. Mousa, ${ }^{1}$ Seif-Eddeen K. Fateen, ${ }^{1}$ and Essam A. Ibrahim ${ }^{2}$ \\ ${ }^{1}$ Chemical Engineering Department, Faculty of Engineering, Cairo University, Giza 12316, Egypt \\ ${ }^{2}$ The University of Texas of the Permian Basin, Odessa, TX 79762, USA \\ Correspondence should be addressed to Seif-Eddeen K. Fateen; fateen@eng1.cu.edu.eg
}

Received 14 October 2013; Accepted 11 December 2013; Published 10 February 2014

Academic Editors: G. Ahmadi and H. S. Roh

Copyright ( 2014 Moataz Bellah M. Mousa et al. This is an open access article distributed under the Creative Commons Attribution License, which permits unrestricted use, distribution, and reproduction in any medium, provided the original work is properly cited.

\begin{abstract}
Circulating fluidized bed steam reformers (CFBSR) represent an important alternative for hydrogen production, a promising energy carrier. Although the reactor hydrodynamics play crucial role, modeling efforts to date are limited to one-dimensional models, thus ignoring many of the flow characteristics of fluidized beds that have strong effects on the reactor efficiency. The flow inside the riser is inherently complex and requires at least two-dimensional modeling to capture its details. In the present work, the computational fluid dynamics (CFD) simulations of the hydrodynamics of the riser part of a novel CFBSR were carried out using two-phase Eulerian-Eulerian approach coupled with kinetic theory of granular flow and $K-\varepsilon$ model. Cold flow simulations were carried under different fluidization regimes. It was found that catalyst of Geldart's type "A" particle is more efficient for flow inside the catalytic reactor and dense suspension upflow (DSU) fluidization regime yields the best homogeneous catalyst distribution in the riser and thus best reactor performance. The optimum range for catalyst flux was found to be higher than $1150 \mathrm{~kg} / \mathrm{m}^{2} \cdot \mathrm{s}$ for a gas flux of $6.78 \mathrm{~kg} / \mathrm{m}^{2} \cdot \mathrm{s}$. It was also noted that the value of $500 \mathrm{Kg} / \mathrm{m}^{2} \cdot \mathrm{s}$ for catalyst flux represents the critical value below which the riser will operate under pneumatic transport regime.
\end{abstract}

\section{Introduction}

Hydrogen has many uses in chemical and energy industries; it is an essential raw material and component for ammonia production and in all hydrocracking plants. It is gaining much attention as the second important energy carrier after electricity [1]. The continuous and fast development in fuel cells technology increased the importance of hydrogen as it is the most efficient feed for fuel cells since it produces only water when utilized [2].

Steam reforming of hydrocarbons is the main production method of hydrogen, especially from methane [3], although the use of higher hydrocarbons [4] and biodiesel $[5,6]$ is gaining more attention. Typically, the process involves a fixed bed reactor with special focus on heat transfer efficiency of the system. New reformer designs are investigated to attempt to overcome the process mass transfer, equilibrium limitations, and catalyst deactivation hurdle. A comparison between different reformers generations is presented in Table 1. The fundamental structure of the circulating fluidized bed membrane reactor (CFBMR), the most recent design, is shown schematically in Figure 1.

Circulating fluidized bed membrane reactors (CFBMR) in general can be operated under different fluidization regimes, most commonly fast fluidization (FF), dense suspension upflow (DSU), or pneumatic transport (PT) regimes; thus, there is virtually no hydrodynamic limit to the flow rates used. Fast fluidization regime is characterized by the wellknown core-annulus structure where an annular structure of down flowing solids is observed near the column walls while the particles load decreases considerably near the column center. On the other hand, Grace et al. [7] observed that in some cases of DSU regime solids may flow upwards over the entire column cross section at high gas velocities. 
TABLE 1: Comparison between fixed bed steam reformers, bubbling fluidized bed steam reformers (BFBMSR), and circulating fluidized bed membrane steam reformer (CFBMSR).

\begin{tabular}{|c|c|c|c|}
\hline & Fixed bed & BFBMSR & CFBMSR \\
\hline $\begin{array}{l}\text { Catalyst particle size } \\
\text { (for the same flow rate) }\end{array}$ & $\begin{array}{l}\text { Large to decrease pressure } \\
\quad \text { drop }(8-16 \mathrm{~mm})\end{array}$ & $\begin{array}{l}\text { Relatively larger than that } \\
\text { of CFBMSR }(0.2-0.35 \mathrm{~mm})\end{array}$ & $\begin{array}{l}\text { Fine particles are used ensuring higher } \\
\text { effectiveness factor } \\
(0.05-0.15 \mathrm{~mm})\end{array}$ \\
\hline Pressure drop & Very high (2-4 atm) & Moderate $(0.2-0.4 \mathrm{~atm})$ & $\begin{array}{c}\text { Low } \\
\text { (around 0.1 atm) } \\
\end{array}$ \\
\hline Effectiveness factor & Very low $\left(10^{-2}-10^{-3}\right)$ & $\operatorname{High}(\sim 1)$ & $\operatorname{High}(\sim 1)$ \\
\hline Gas flow rate & Low & Medium & High, allowing for higher productivity \\
\hline Catalyst regeneration & Shutdown required & Shutdown typically needed & $\begin{array}{l}\text { No need for shutdown due to the } \\
\text { presence of downer; also regeneration } \\
\text { allows autothermicity of the operation }\end{array}$ \\
\hline $\begin{array}{l}\text { Thermodynamic } \\
\text { equilibrium limitation }\end{array}$ & $\begin{array}{c}\text { Existing due to absence of } \\
\text { hydrogen membranes }\end{array}$ & $\begin{array}{l}\text { Not existing because of } \\
\text { hydrogen removal }\end{array}$ & Not existing because of hydrogen removal \\
\hline
\end{tabular}

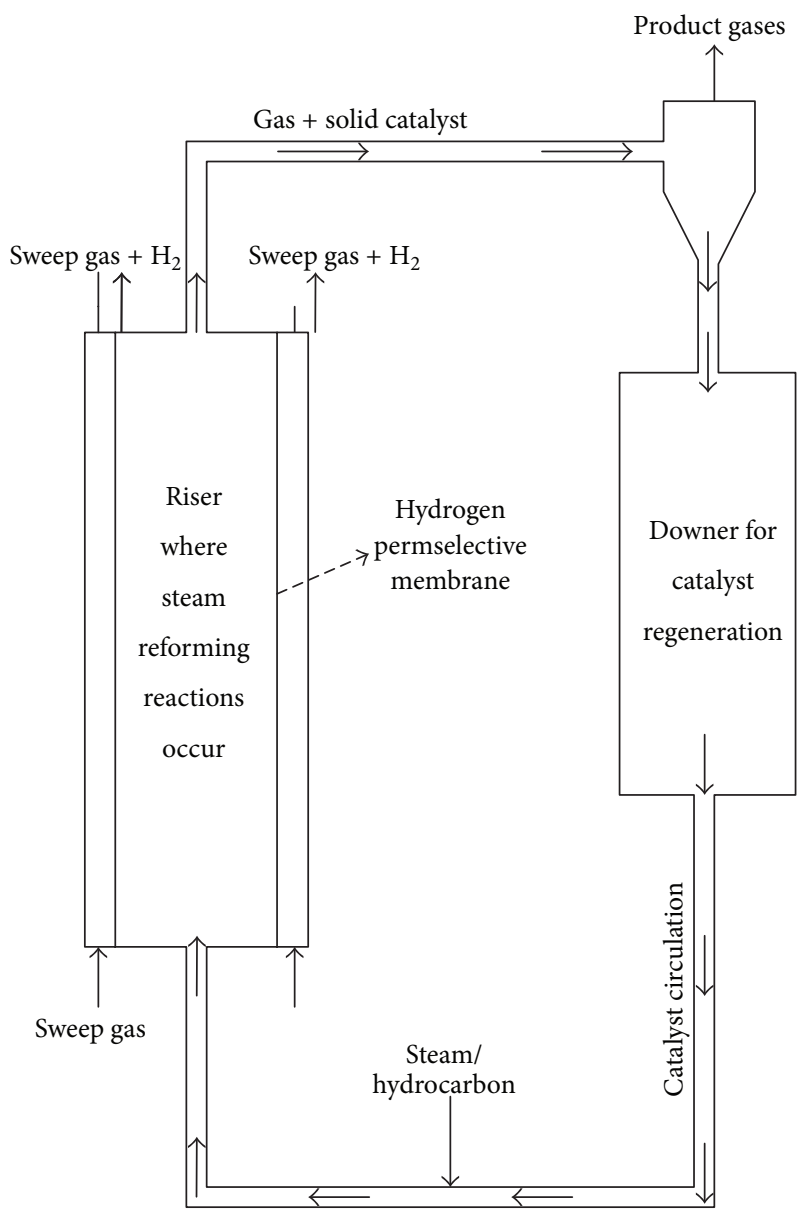

FIGURE 1: Novel circulating fluidized bed steam reformer, reproduced from [8].

This was attributed to a higher flux of solids than in FF regime. Also DSU is characterized by solids volume fraction higher than 7\% [7] to distinguish it from "pneumatic transport" where solids are also moving upward over the whole cross section. The transition conditions between the three regimes are shown in Figure 2.

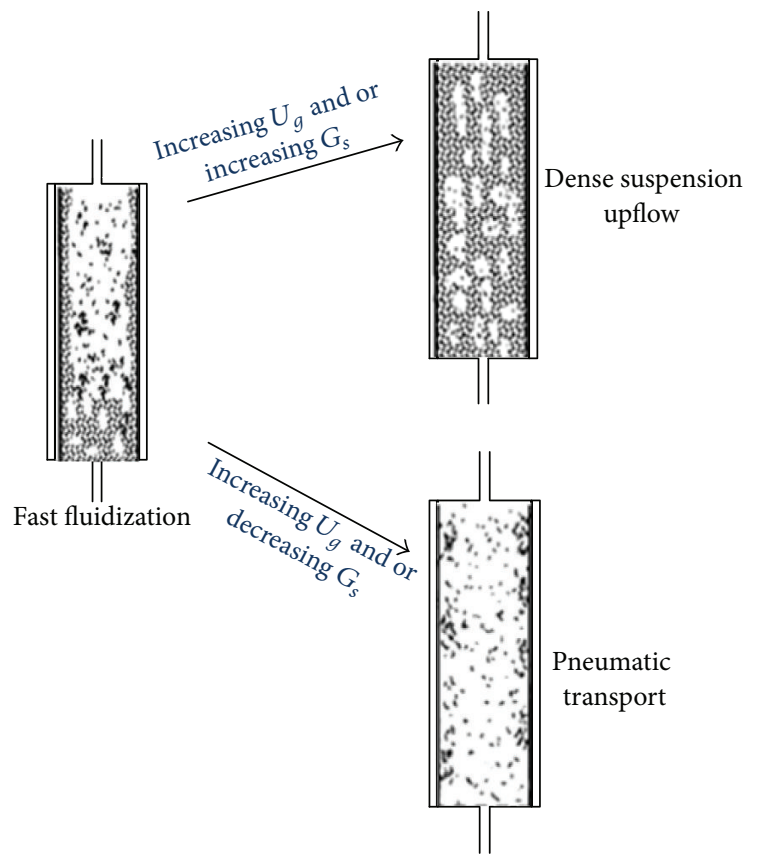

FIGURE 2: Schematic representation of transitions between FF to DSU or PT, reproduced from [9].

Several regime maps have been proposed in the literature for the direct predetermination of the gas-solid contact regime. The map developed by Grace [10] has not considered the effect of gas flux on prevailing regimes and thus failed to differentiate between FF, DSU, and PT. Kim et al. [11] proposed a new flow regime map to distinguish between the three regimes. Their map was fitted from many experimental data for flows in different circulating fluidized bed reactors (CFBRs) and considered the variation in flow with riser height due to the change in particles void fraction.

Both Grace [10] and Kim et al. [11] maps were used in the current work to predict the prevailing regimes due to the absence of any experimental data for the geometry and conditions used in the work. The unavailability of experimental data also prevented quantitative validation of 
the present model results and only qualitative comparisons were performed against experimental data from different risers' geometries. Previous qualitative validations were reported in the literature due to the lack of experimental data for similar reactor geometries and flow conditions [12-14].

To predict the proper hydrodynamic regime for optimum catalyst selectivity and process yield, a rigorous mathematical model for the CFBSR is needed. This cold flow model, even without including membrane effects, will provide guidance to pilot reactor testing through investigating the influence of reactor configuration and fluidization regime on hydrodynamics and catalyst circulation. The absence of kinetics effect and membranes is expected to lead to discrepancies from the actual design, but this work presents a forerunner study of a membrane CFBSR. This approach of breaking sophisticated physical phenomena into different modeling levels has been employed by many researchers especially for CFD modeling of CFBRs [12, 1517]. This study is also useful for nonmembrane CFBSR, keeping in mind the relatively higher cost of hydrogen membrane reactors owing to the membranes cost, which is expected to decrease in the coming decade [18-20]. At this stage of the novel steam reformer study, the authors are concerned with the flow characterization under different fluidization regimes. The following stages will comprise the coupling of the flow hydrodynamics with the reaction kinetics and the inclusion of hydrogen membranes. This work helps in simplifying the complex multiphase flow behavior inside the riser of a novel high yield hydrogen steam reformer.

The remainder of the paper will summarize the previous work done on modeling the riser section of CFBSR, followed by a brief description of the used model, which was detailed in an earlier work by the present authors [21]. The results and discussion are then presented and the key findings are summarized in the conclusions section.

\section{Model Formulation}

Chen et al. [22] simulated the flow inside the CFBSR riser using a plug flow model with no axial dispersion, thus discarding many hydrodynamics details which lead to inaccurate model predictions. Their work did not consider the nonuniform radial distribution of catalyst particles characterizing flow in CFBR nor the continuous gas-catalyst interactions, which affect the interphase mass and heat transfer and the estimated residence time distribution of the catalyst. Moreover, they applied the assumption of no-slip between the gas and solid phases results in identical residence time for the gas and catalyst which is in disagreement with many experimental findings [23-25].

Due to such limitations of the unidirectional model, the authors of this study considered the use of computational fluid dynamics to understand the hydrodynamics effects inside the riser part of the CFBSR system. The modeling of the complex hydrodynamics and reaction behavior inside the CFBSR is carried out in stages. In the first phase, the flow under different fluidization regimes without membranes and in absence of chemical reactions is to be characterized. In the following stages the flow behavior will be coupled with the reaction kinetics. The flow behavior inside the CFBSR riser under the fast fluidization regime was characterized and the results were published in an earlier study [21]. The reactor dimensions used in the present work are based on earlier findings [22], where it was shown that a $2 \mathrm{~m}$ tall reactor of $\sim 4^{\prime \prime}$ diameter will be enough for $\sim 95 \%$ conversion of methane in presence of hydrogen membranes. The relatively short length of the reactor can allow for its use in conjunction with fuel cells in automotives.

The solved cases under FF regime showed that the CFBSR must be operated under high density and high flux conditions, as defined by H. Zhu and J. Zhu [26], using nickel/alumina catalyst of Geldart's "A" type [27]. Different Geldart's type particles have been tested in one of our earlier studies [21] and type "A" was found to give the best particles flow mixing for high density and high flux conditions. In addition, the FF regime was found to be incompatible with fast reactions under quick catalyst deactivation as is the case for steam reforming. This analysis was attributed to the high solids residence time distribution (RTD) caused by the catalyst back mixing [21]. Diminished reactor yield and selectivity were also shown owing to the unequal solids RTD along the reactor. Our previous results also suggested that the DSU regime might be more suitable, relative to FF regime, for the fast steam reforming reactions due to the observed higher catalyst radial uniformity distribution.

This work focuses on investigating the suitability of DSU regime for the CFBSR in comparison to the FF regime and on preliminary optimization of the DSU conditions. The previously developed two-dimensional CFD model [21], for the riser part (without membranes) of the CFBSR, will be used for the flow modeling. The model equations of this multiphase flow system were solved numerically using the commercial CFD package FLUENT 6.3.2. The model results were not validated qualitatively with experimental data due to the lack of data for similar geometry and operating conditions appropriate for the small-scale production of hydrogen for fuel cell applications [28]. Subsequently, a parametric study was conducted for some of the model numerical parameters. A summary of the solved cases is shown in Table 2.

The inlet gas composition was held constant together with a temperature of $923 \mathrm{~K}$ and pressure of $5 \mathrm{~atm}$ for all the cases, while the gas mass flux, $G_{g}$, catalyst mass flux, $G_{s}$, and inlet catalyst volume fraction, $\varepsilon_{s}$, were varied. The inlet gas consisted of methane, water vapor, carbon dioxide and hydrogen at compositions of $20,72.5,2.5$, and $5.0 \%$ respectively. The reactor dimensions are based on the results of the process kinetics model by Chen et al. [22] of $2 \mathrm{~m}$ tall and $\sim 4^{\prime \prime}$ diameter.

The inlet gas velocity was defined as a fully developed one-seventh power law turbulent profile using user defined functions (UDF) written in "C" language and then compiled in FLUENT. The superficial gas velocity at the inlet varied between $\sim 3$ and $6 \mathrm{~m} / \mathrm{s}$ for the different simulation cases based on the inlet gas flux. The velocity values, which can be directly calculated from the gas flux and density, and the turbulent flow profile were justified by the simulation results. 
TABLE 2: Summary of used inlet flow conditions for the different cases solved.

\begin{tabular}{lcccc}
\hline \multirow{2}{*}{ Operating condition } & \multicolumn{2}{c}{ Dense suspension upflow $(\mathrm{DSU})$} & Fast fluidization & Pneumatic transport \\
& Case 1 & Case 2 & Case 3 & Case 4 \\
\hline$G_{s}\left(\mathrm{~kg} / \mathrm{m}^{2} \mathrm{~s}\right)$ & 1150 & 500 & 1500 & 250 \\
$G_{g}\left(\mathrm{~kg} / \mathrm{m}^{2} \mathrm{~s}\right)$ & 6.78 & 6.78 & 3.4 & 6.78 \\
$\varepsilon_{s}$ & 0.2 & 0.2 & 0.2 & 0.2 \\
\hline
\end{tabular}

TABLE 3: Summary of the used Eulerian-Eulerian model.

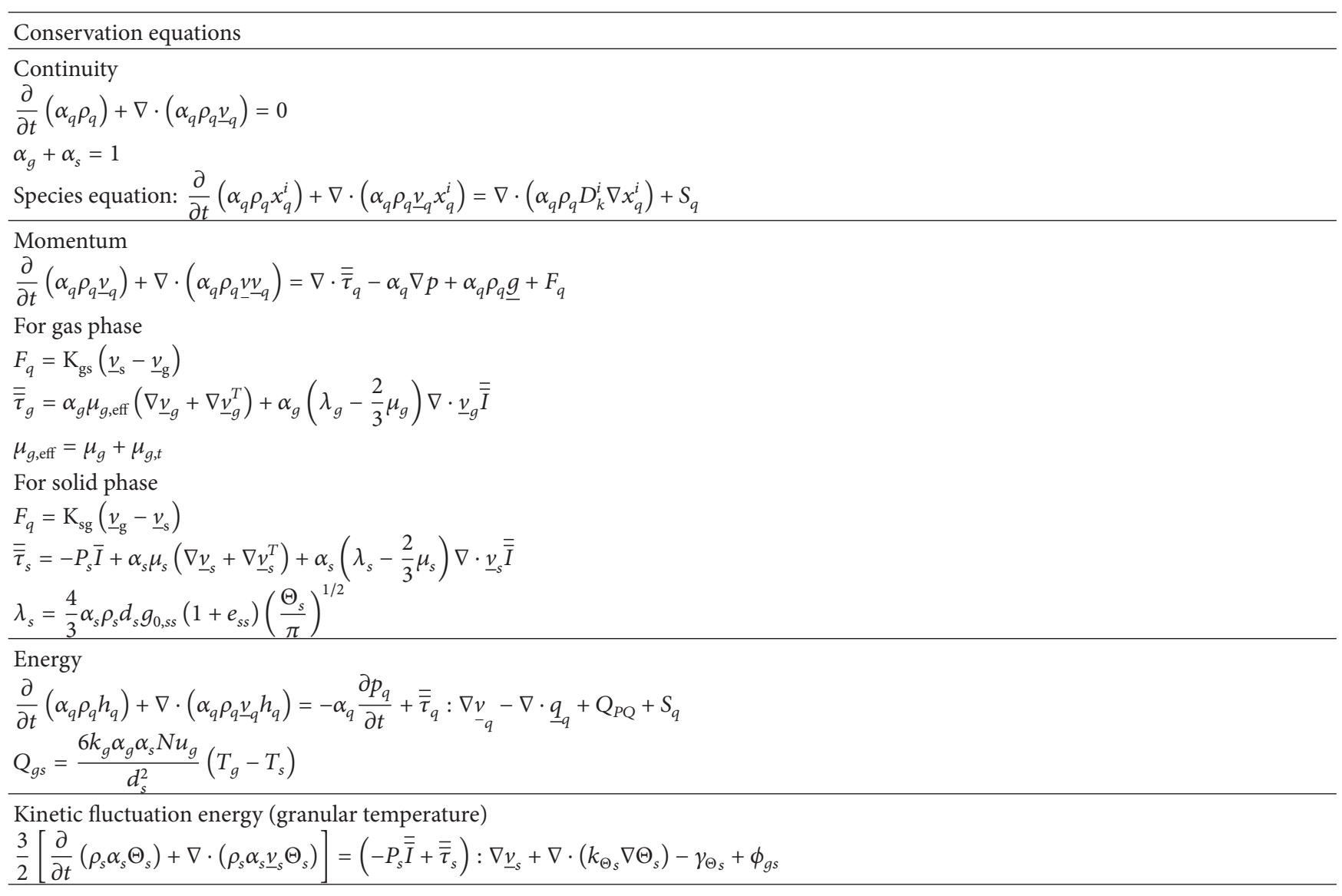

2.1. CFD Modeling. The simulations were carried using twophase Eulerian-Eulerian approach coupled with kinetic theory of granular flow (KTGF) with the addition of frictional stress models and turbulence was considered using a $K-\varepsilon$ model for each phase (gas and granular phases).

The details of the model equations and the solution procedure were presented earlier [22]. A list of the equations is shown in Table 3.

In comparison to single-phase flows, the number of terms to be modeled in the momentum equations in multiphase flows is large, and this makes the modeling of turbulence in multiphase simulations extremely complex. In the $(k-\varepsilon)$ turbulence model, the continuous phase turbulence is modeled using transport equations for turbulent kinetic energy, $k$, and turbulent energy dissipation rates, $\varepsilon$, which are then used to determine the turbulent viscosity. The effective gas phase viscosity, part of the gas stress tensor, is then determined by adding the turbulent viscosity, to the gas dynamic viscosity. The same approach was applied for the solid phase, where a turbulent component of the solids viscosity could also be calculated by solving two extra transport equations for turbulent kinetic energy and dissipation of the solids phase; then the effective solids viscosity is $\mu_{s, \mathrm{eff}}=\mu_{s}+\mu_{s, t}$.

Due to the effect of drag force models on the catalyst distribution in the riser, different models have been tested. There are many drag force models available in the literature though the two commonly used are those by Syamlal and O'brien [29] and Gidaspow [30], followed by those of Wen and $\mathrm{Yu}$ [31] and Arastoopour et al. [32]. The last two are known to be used for dilute systems which is not the case in this work. Both Syamlal and O'brien [29] and Gidaspow [30] models showed comparable results for our setup. The results presented in this work are using the Syamlal and O'brien [29] drag force model. 


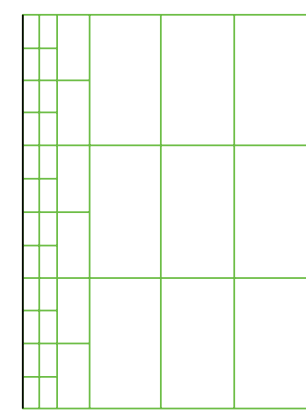

(a)

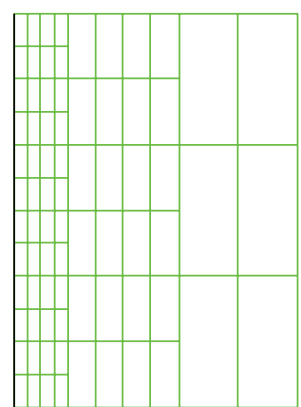

(b)

FIGURE 3: Section beside the riser wall before adaptation (a) and after adaptation (b) to show how the number of cells was increased for the grid dependency test.

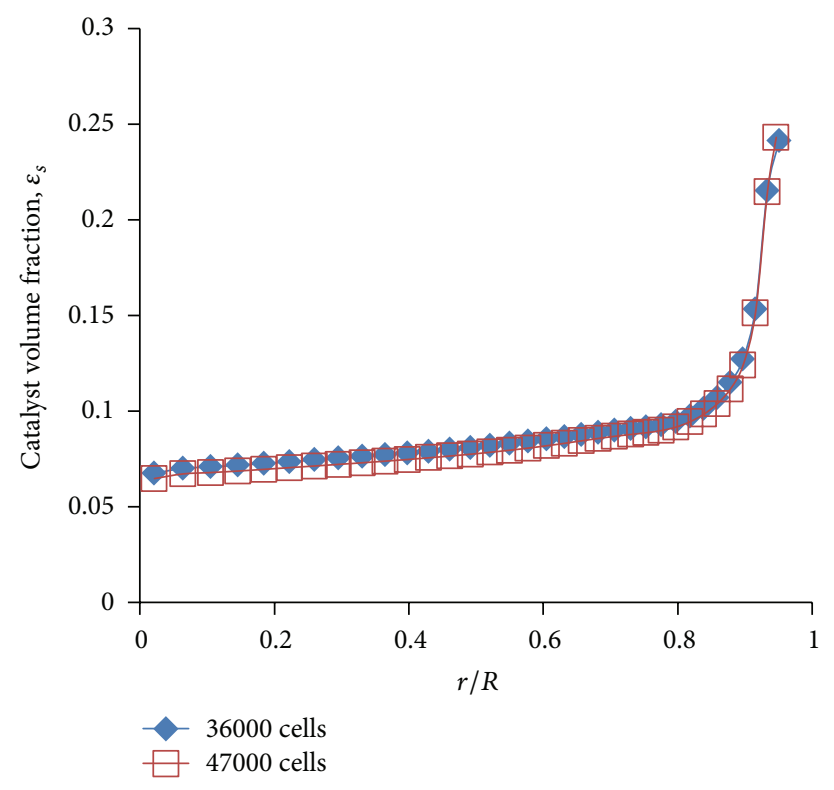

(a)

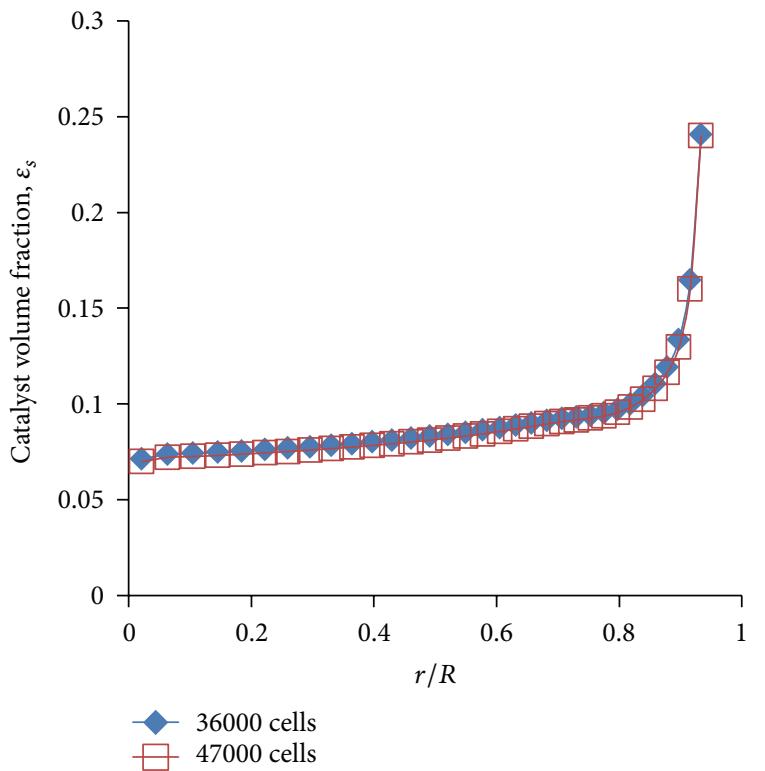

(b)

FIGURE 4: Radial profiles of catalyst volume fraction and axial velocity after $40 \mathrm{sec}$ of flow at 0.75 and $1.5 \mathrm{~m}$.

2.2. Modeling Parameters. Some of the parameters that appear in the different conservation and constitutive equations are the radial distribution function $\left(g_{0, s s}\right)$, solid-wall restitution coefficient $\left(e_{w s}\right)$, and specularity coefficient $(\phi)$. The values of those parameters were reported to be critical for the accuracy of the CFD model. Accordingly, the sensitivity of the model to these parameters was examined in the present parametric study.

Although there are many empirical correlations in the literature to represent the radial distribution function, most of them are dedicated for cases of more than one solid phase, different particle size grains. By setting number of solid phases to one, a correlation may be obtained for the current single particle size case, but this is not recommended especially for empirical equations. Thus, only the equations correlated for single size particles will be considered. Two correlations in the literature for the unisize case were used in most engineering simulations [23], Lun and Savage [33] and Ogawa et al. [34]. The former [33] will be adopted in the present work.

Sinclair and Jackson [35] and other authors [36,37] found that their models for gas-solid flow in risers exhibited extreme sensitivity with respect to the values of restitution coefficients. On the contrary, Almuttahar and Taghipour [38] reported that the wall restitution coefficient has a minor effect on the flows in CFBs for Geldart's A particles. This disagreement could be resolved by incorporating turbulence models for both phases $[36,39,40]$. Due to such disagreement, the sensitivity of the results to the wall restitution coefficient $\left(e_{w s}\right)$ was examined in this study. Restitution coefficients in CFBRs usually have values ranging from 0.9 to 0.99 [41-44] depending on the particle types and flow conditions. Other authors $[45,46]$ reported that using a value of unity can lead to better results in some cases but that approach was opposed by $[41,44]$ since this elastic collision assumption leads to the unphysical disappearance of solid clusters. 


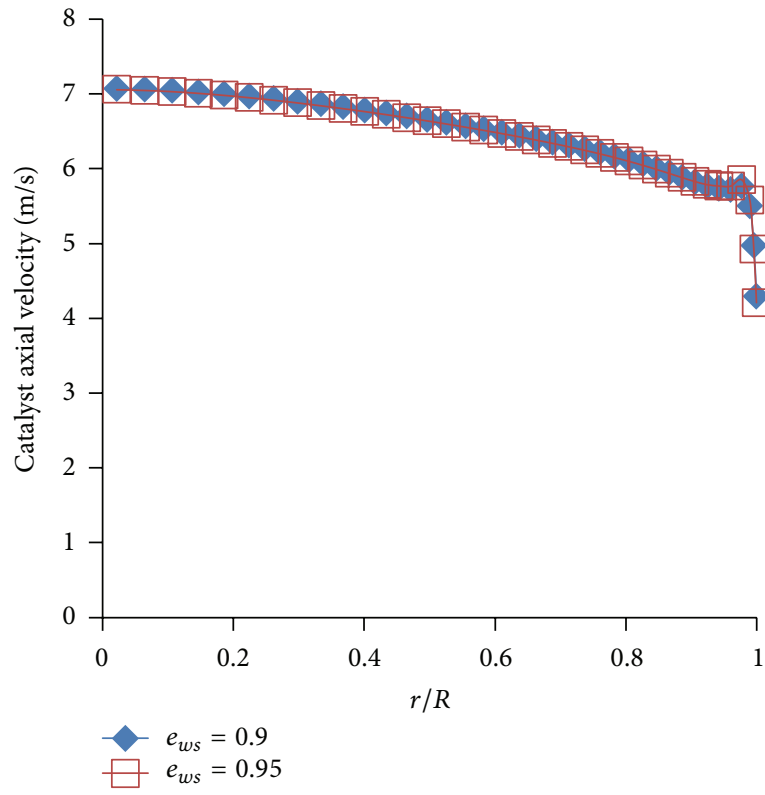

(a)

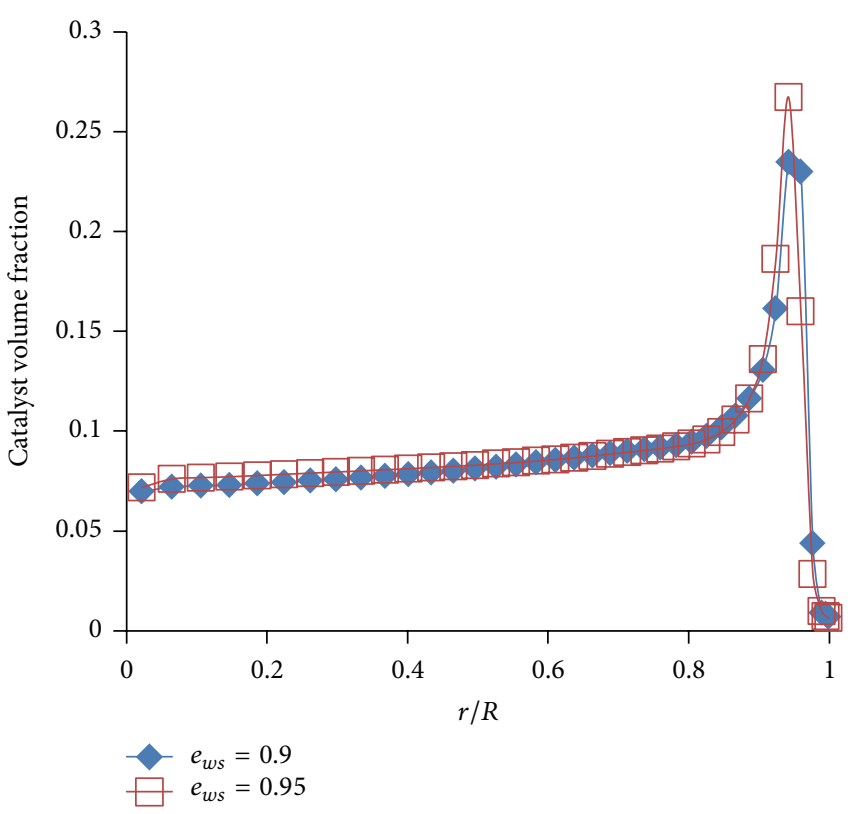

(b)

Figure 5: Radial profiles of catalyst volume fraction and axial velocity at $1 \mathrm{~m}$ after 40 seconds of flow for different particle-wall restitution coefficient values.

Specularity coefficient $(\phi)$ is a measure of the fraction of tangential collisions which transfer momentum to the wall. It is equivalent to one minus the tangential restitution coefficient [47] and was previously estimated to range from 0.5 to $0.6[48,49]$. Almuttahar and Taghipour [38] showed that a specularity coefficient close to zero (which corresponds to free-slip at the wall) gave better agreement with experimental results in a high density CFB, which also agreed with Ranades' [47] findings that decreasing the specularity coefficient leads to a flatter solids velocity profile. It was also shown by $\mathrm{Li}$ et al. [50] that the solid-phase wall boundary condition needs to be modeled carefully due to its considerable impact on the hydrodynamics. Again, the sensitivity of the results to the specularity coefficient was examined in this study.

\section{Results and Discussion}

3.1. Grid Independence and Numerical Parameters Sensitivity. To confirm that the CFD results are independent of the mesh size, simulations were solved for 36000 cells and 47000 cells for the first case and then results were compared. The number of cells was increased using the grid adaptation option in FLUENT by refining the adjacent cells to the walls or the whole computation domain. Both approaches confirmed the grid independence for the lower number of cells (36000). Only the results of refining up to 4 cells beside the walls are shown in Figure 3.

The adaptation was performed after 10 seconds from the start of the flow and both cases were run for 30 more seconds; then the radial solids concentration and axial velocity profiles, at different elevations, were compared. As shown in Figure 4, results turned out to be nearly the same which indicates that the coarser mesh is sufficient for providing practically mesh independent results and thus was used through the rest of this study.

Figure 5 shows the sensitivity of the simulation results to varying the wall restitution coefficient $\left(e_{w s}\right)$. No significant change occurred for the catalyst volume fraction and its axial velocity, at the middle of the riser, by varying the restitution coefficient from 0.9 to 0.95 . This finding agrees with what Neri and Gidaspow [51] reported that the wall restitution coefficient plays only minor roles in a CFBR with Geldart's type "A" particles. They used two values for $e_{w s}, 0.8$ and 0.96 , and found that $e_{w s}$ has little effect on solids concentration near the wall but does not affect the overall flow pattern. A value higher than 0.95 will lead to an increase in the catalyst concentration at the wall by only small fraction but will not influence the overall dynamic behavior of the flow.

It is clear from Figure 6 that increasing specularity coefficient value from 0.01 to 0.6 has only slight effect at near wall region but has no influence on the overall flow dynamics. A higher specularity value indicates rougher wall and hence a lower catalyst velocity near the wall and slightly higher volume fraction as shown in the figure.

3.2. Dense Suspension Upflow Regime. The transient behavior of flow development in the riser for case number 1 is shown in Figure 7. Initially the riser was empty and then the gas and catalyst were introduced from the bottom of the riser. The gas was introduced at the inlet boundary as a fully developed turbulent profile. After 1 second, it was found that the flow is still developing where the catalyst has nearly reached the middle of the riser height. Owing to the high gas inlet velocity $(\sim 6 \mathrm{~m} / \mathrm{s})$, relative to catalyst inlet velocity 


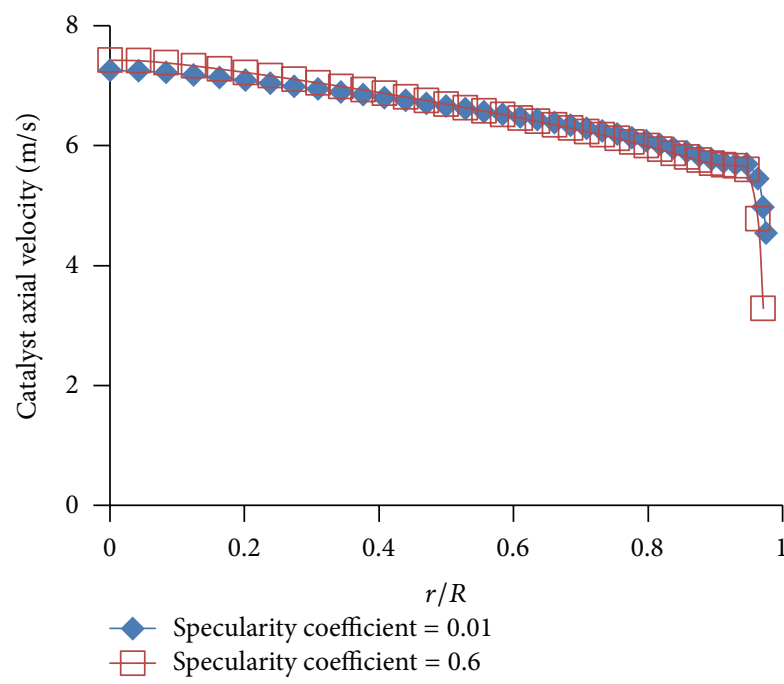

(a)

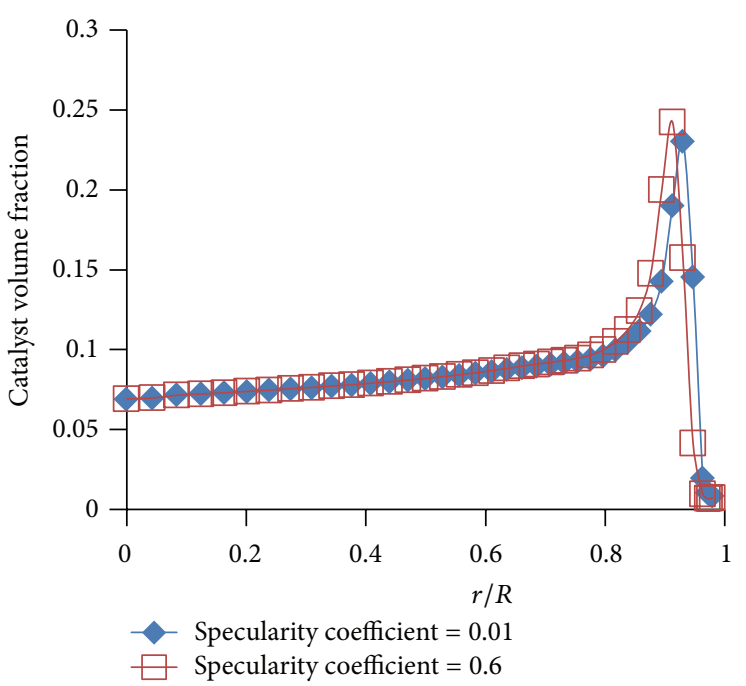

(b)

FIGURE 6: Radial profiles of catalyst volume fraction and axial velocity at $1 \mathrm{~m}$ after 40 seconds of flow for different specularity coefficient values.

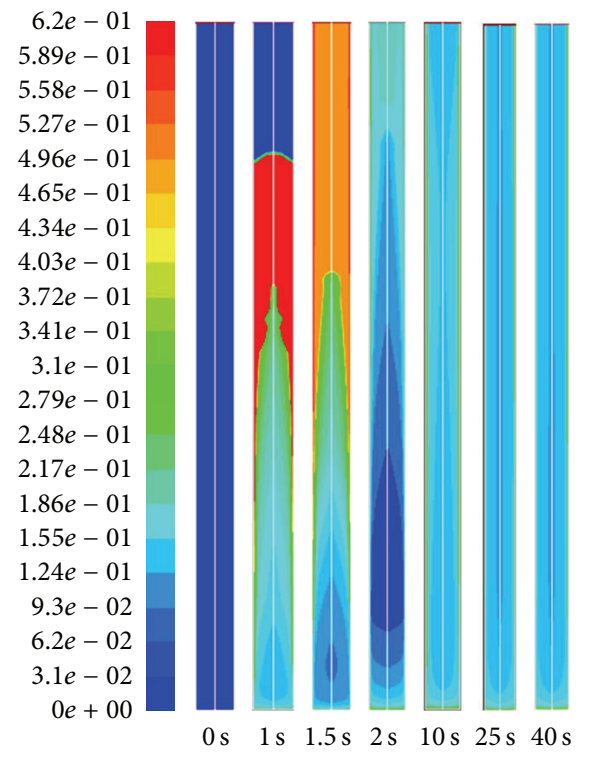

FIgURE 7: Transient distributions of catalyst volume fraction in the riser operating at DSU regime.

$(\sim 2 \mathrm{~m} / \mathrm{s})$, the catalyst was mainly carried by the gas and was dragged towards the riser wall as it moved upward. The flow was developing inside the riser with noticeable changes in catalyst volume fraction in the axial direction for the first 15 seconds of the flow, after that the main flow variations were occurring in the radial direction for the next 10 seconds. The contours of catalyst volume fraction were nearly similar at 25 seconds and 40 seconds from the beginning of the flow, which infers the occurrence of quasisteady state condition starting after $\sim 25$ seconds from the beginning of the flow. After 40 seconds of the flow, there was no net downwards flow of the catalyst near the wall; catalyst particles are moving upward through the whole riser cross section which confirms the establishment of the DSU flow as shown in Figure 8.

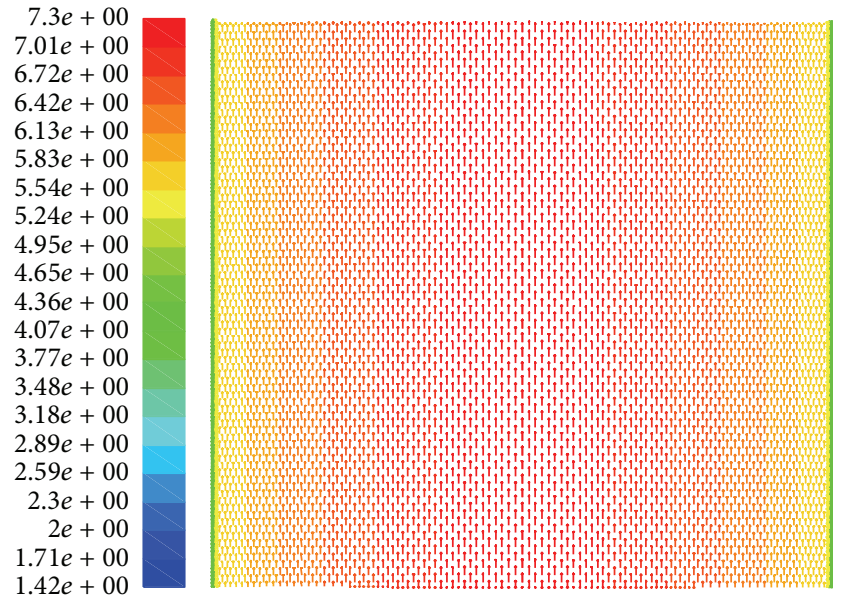

FIGURE 8: Catalyst velocity vectors between 0.9 and $1 \mathrm{~m}$ of the riser after 40 seconds of the flow in DSU case.

The axial profile for the catalyst volume fraction (Figure 9) showed a pattern similar to that reported by Lim et al. [23] for dense flows. At the bottom of the riser there is a dense, relatively short region followed by a nearly constant profile over the rest of the riser. This is in qualitative agreement with the experimental results of [23] and our model predictions. The presence of dense bottom zone was also reported by other authors $[52,53]$. It is also clear from Figure 9 that the average catalyst volume fraction in the riser is around $10 \%$ (void fraction of $90 \%$ ) which again confirms the DSU regime, since the average volume fraction is higher than $7 \%$, as suggested by [11].

Figure 10 shows that the axial velocity of catalyst at the riser wall is $\sim 4 \mathrm{~m} / \mathrm{s}$ at $1 \mathrm{~m}$ height of the riser. This relatively high velocity leads to a more uniform catalyst radial velocity profile which is a characteristic feature of DSU regime 

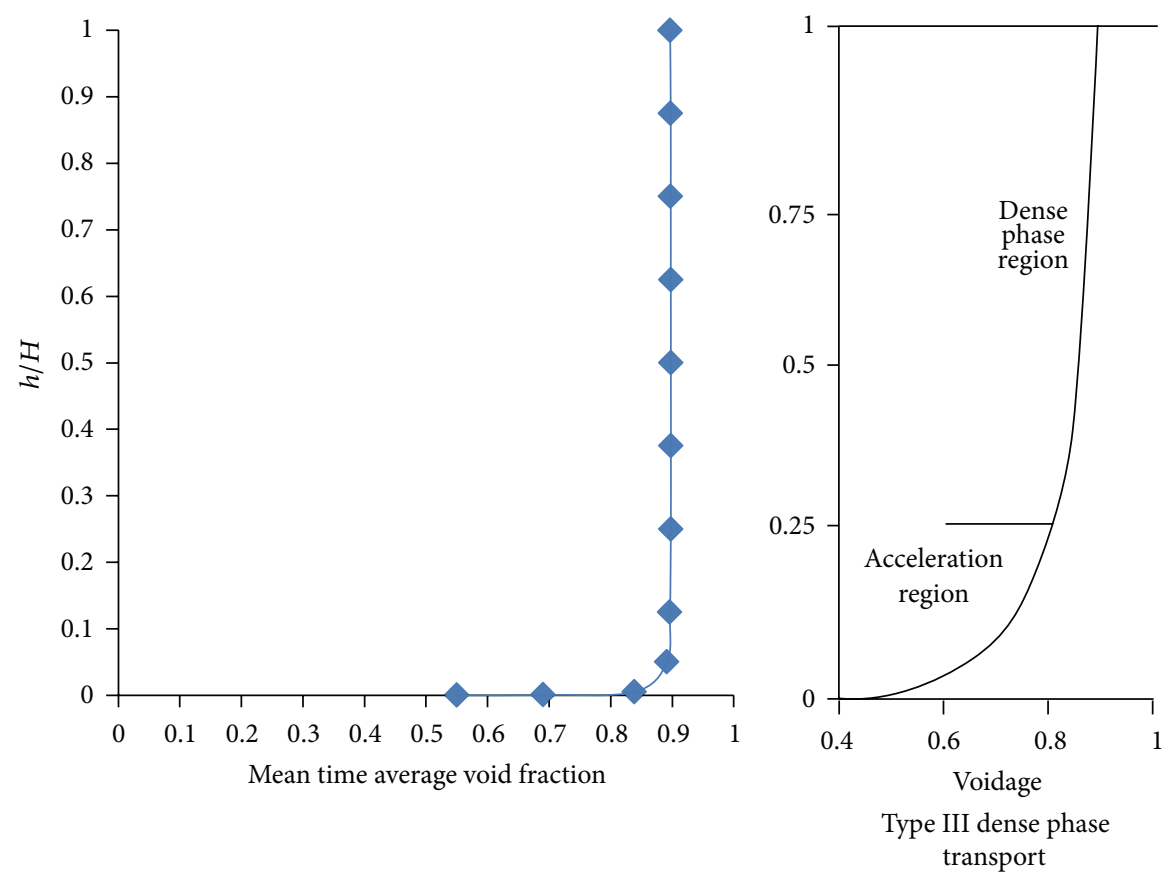

FIGURE 9: Axial profile for catalyst volume fraction in the riser operating at DSU regime qualitatively validated against [23].

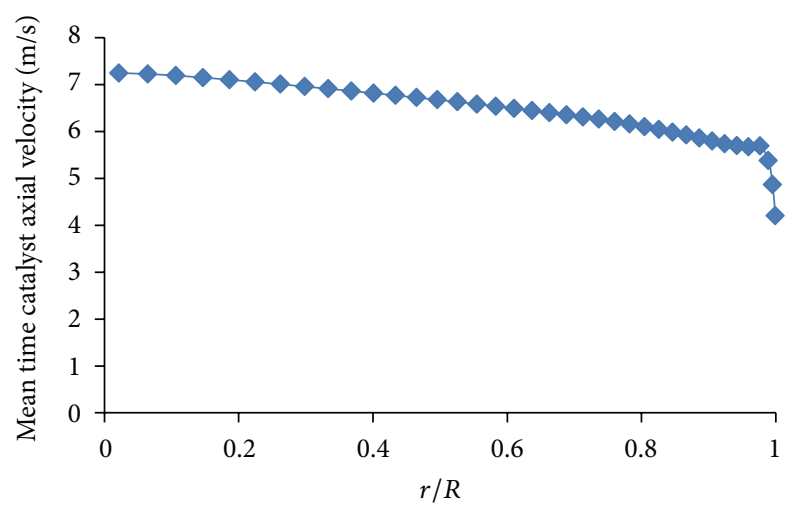

FIGURE 10: Radial profile of catalyst axial velocity at $1 \mathrm{~m}$ of the riser operating in DSU regime.

together with more uniform catalyst radial volume fraction profile (Figure 11) compared to those of FF regime [11, 38, 54].

\subsection{Behavior of Catalyst Close to the Riser Wall. Although} the radial profile of catalyst volume fraction, as shown in Figure 11, agrees qualitatively with many works in the literature, the absence of catalyst just beside the wall was rarely referred to in the literature. Passalcqua [55] pointed out that the absence of catalyst in the vicinity of the wall is physically acceptable even if not reported experimentally, since as the catalyst particles hit the wall they move a little bit away and do not stick to the wall. Also, in the experimental literature for granular flow in CFBR, there are no references to measurements that were taken just beside the wall because probes may not have accurate results for those regions and

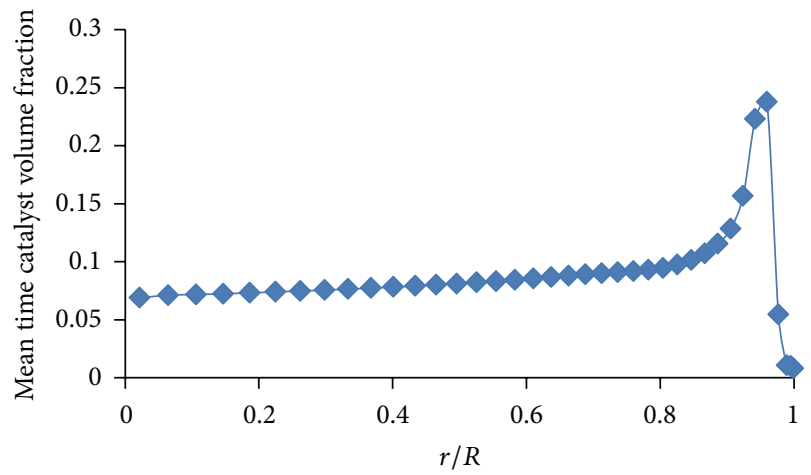

FIGURE 11: Radial profile of catalyst volume fraction at $1 \mathrm{~m}$ of the riser operating in DSU regime.

even the laser doppler anemometers (LDA) are not highly reliable for solids measurements.

Radial profile of granular temperature (Figure 12) shows that it has a maximum value just beside the wall, about 4 orders of magnitude greater (Figure 12(b)) than the rest of the cross section (Figure 12(a)), and is minimum at the region of highest catalyst concentration. Catalyst particles hit the wall and get reflected; as a consequence the velocity variance is high, even though the mean flux across the wall is zero due to the impermeability condition. A high velocity variance leads to a high granular temperature, since granular temperature is proportional to the square of velocity variance, and thus a lower particle concentration.

Grid adaptation was carried out for near wall cells (Figure 3) and a lower wall restitution coefficient was used $\left(e_{w s}=0.6\right)$ to check if that will change the trend near the wall, but results turned out to be roughly the same with catalyst 


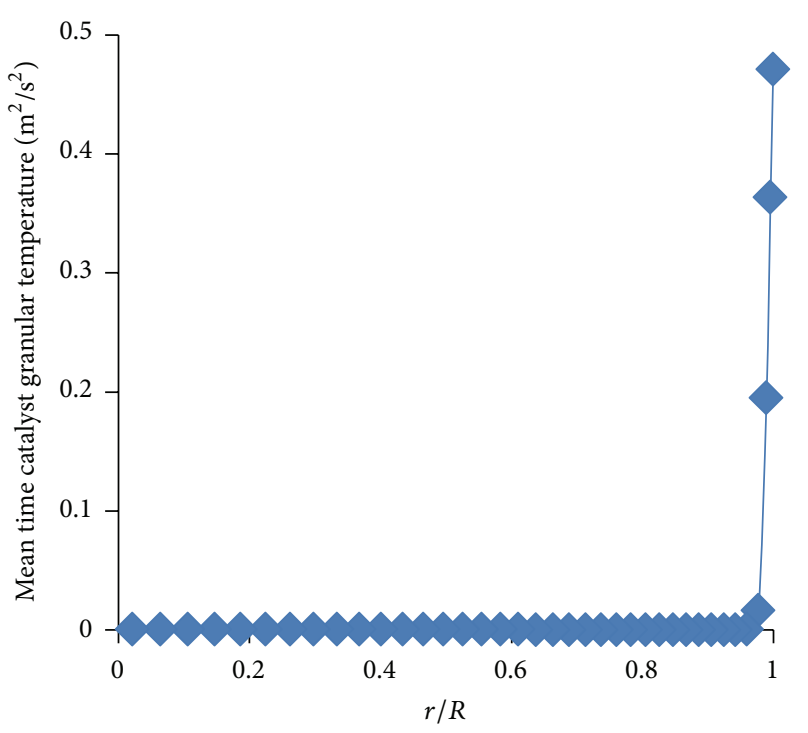

(a)

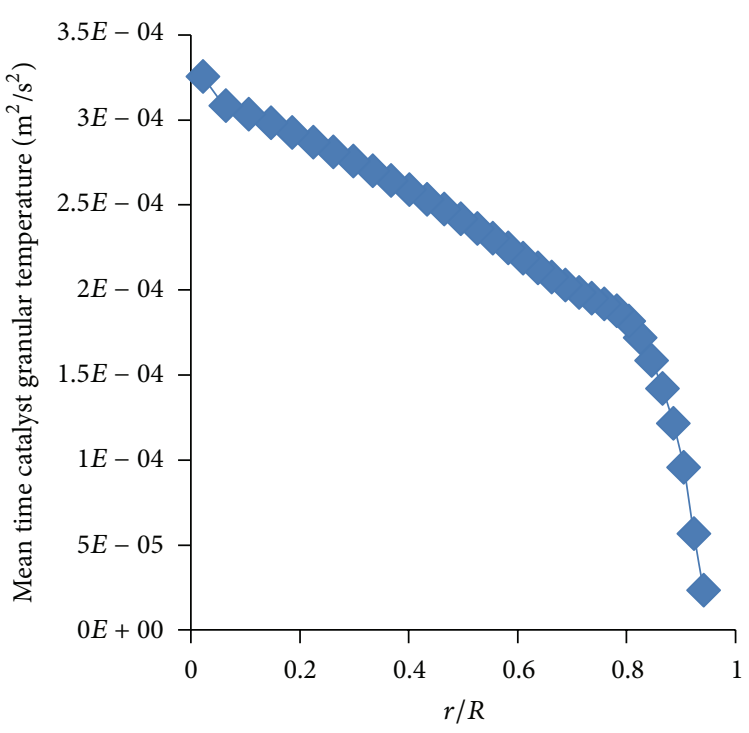

(b)

FIGURE 12: Radial profile of catalyst granular temperature at $1 \mathrm{~m}$ of the riser operating in DSU regime with near wall points (a) and without near wall points $(\mathrm{b})$.
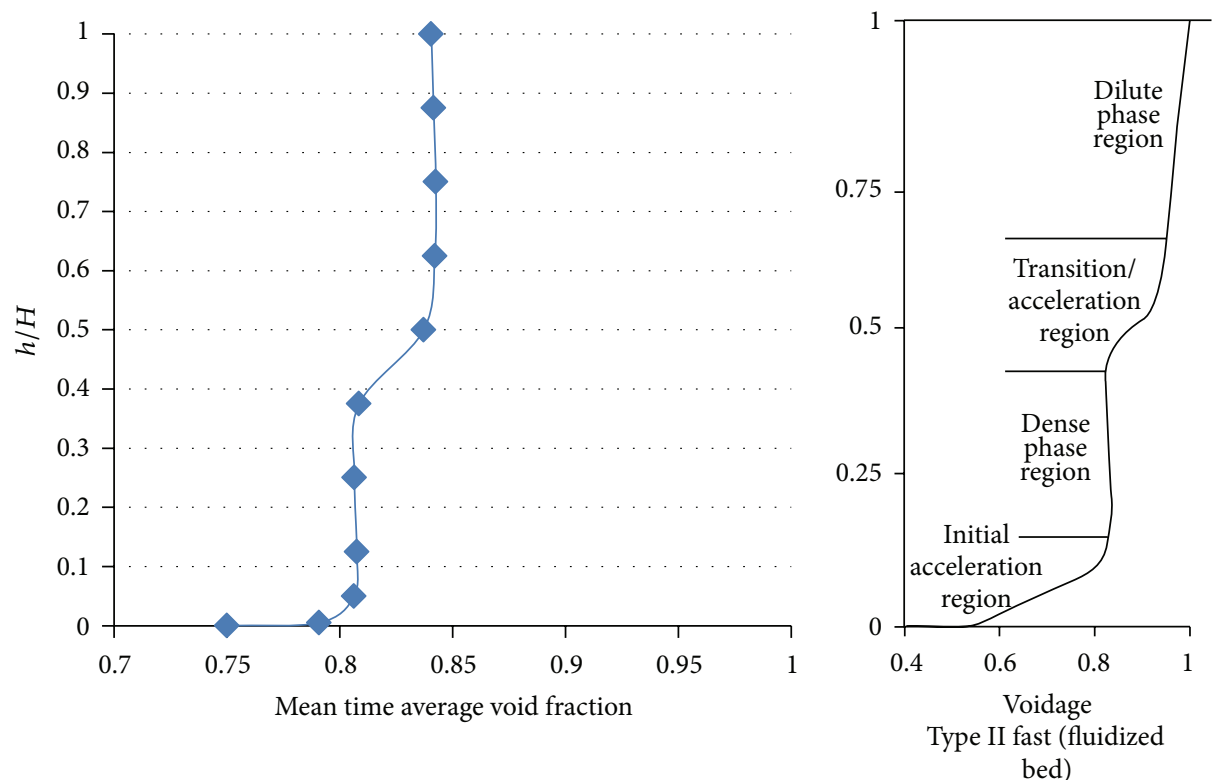

FIGURE 13: Axial profile for catalyst volume fraction in the riser operating at FF regime qualitatively validated against [23].

volume fraction being the lowest just beside the wall. This observation can be attributed to the limitations of available models. The failure of models to accurately predict the radial segregation of solids and therefore underestimations of the solids concentration at the walls were reported by some CFBRs modelers $[42,49,56]$. Simplifications in CFBRs models, like neglecting electrostatic forces between particles and reactor walls, were introduced for the reduction of computational difficulties of the complex multiphase models.

3.4. Comparing DSU and FF Regimes inside the CFBSR. The solved case under FF regime (case 3), which was presented in previous work [21], showed a DSU regime in the first third of the reactor height, followed by the FF regime over the rest of the riser height. The comparison of the catalyst radial distribution in the two zones suggested a higher quality of the DSU regime over the FF for the fast reactions like the steam reforming under investigation in this study. The flatter profile of catalyst volume fraction over the riser diameter reveals better catalyst mixing and homogeneity in the radial direction.

The quality of axial mixing was also examined by the axial profile of the mean time catalyst void fraction. By comparing Figures 9 and 13, it is evident that DSU regime 
offers better axial mixing all over the riser. While in DSU case the axial profile of mean time catalyst void fraction is nearly vertical, and that of FF is subjected to variations and transition zones. Thus, DSU regime is more suitable for carrying steam reforming in the riser from the point of higher axial homogeneity. Moreover, the lower catalyst residence time and more uniform RTD favored by DSU regime assure its advantages over $\mathrm{FF}$ regime for steam reforming reaction.

It can be concluded that the flow properties in DSU regime are favorable for short contact time reactions like steam reforming. With high solids loading and relatively more homogeneous flow structure in both radial and axial directions, better reactor performance is expected. The absence of back mixing leads to a more homogeneous residence time distribution, important to ensure good process selectivity and conversion.

3.5. Optimum Conditions Range at DSU Regime. To investigate the effect of inlet catalyst volume fraction on the overall flow and catalyst volume fraction, a DSU case was solved with exactly the same setup but with higher inlet catalyst volume fraction. It was found that the axial and radial profiles for cross-sectional average catalyst volume fraction are nearly the same for both cases with the main difference at a short dense region at the first few centimeters of the riser. This dense region may be of great use in reactive system where much of the feed can get reacted there, but that needs careful study using reactive cases together with inlet geometry effect using available inlet designs for CFBRs which is not included in this study.

The amount of circulating catalyst plays an important role in increasing yield and impacts the flow hydrodynamics. As the catalyst flux increases, more uniform catalyst distribution in the axial direction can be attained. The flow under catalyst flux of $1150 \mathrm{~kg} / \mathrm{m}^{2} \cdot \mathrm{s}$ (Case number 1) was compared to those at fluxes of $250 \mathrm{~kg} / \mathrm{m}^{2} \cdot \mathrm{s}$ and $500 \mathrm{Kg} / \mathrm{m}^{2} \cdot \mathrm{s}$ (Cases number 2 and 4), all for gas flux of $6.78 \mathrm{Kg} / \mathrm{m}^{2} \cdot \mathrm{s}$. The axial profile for the densest flow $\left(1150 \mathrm{Kg} / \mathrm{m}^{2} \cdot \mathrm{s}\right)$ showed the most uniform axial catalyst distribution with nearly vertical profile as shown in Figure 14. The $250 \mathrm{Kg} / \mathrm{m}^{2}$.s case shows a very dilute flow with catalyst average concentration of about $3 \%$ which implies a pneumatic transport regime unsuitable for reactive flows due to the relatively low catalyst concentration. The $500 \mathrm{Kg} / \mathrm{m}^{2} \cdot \mathrm{s}$ case has nearly an average catalyst fraction of about $7 \%$ which is considered the limit between DSU and PT regimes.

Thus, for DSU regime the higher the catalyst flux, the more uniform the profile and thus the better the mixing in axial direction. It can be deduced that a DSU regime with even higher catalyst flux $\left(1500 \mathrm{Kg} / \mathrm{m}^{2} \cdot \mathrm{s}\right.$ for say) can provide more suitable conditions for the steam reforming reaction from axial mixing stand point.

However, it is important to note that the flow distribution in DSU is still subject to significant radial gradients, with considerably higher concentrations of particles near the walls than in the core of the riser. In contrast to the effect of increasing catalyst flux on axial mixing, here the radial homogeneity decreases with increasing the flux as shown in Figure 15. Those two contradicting effects must be taken

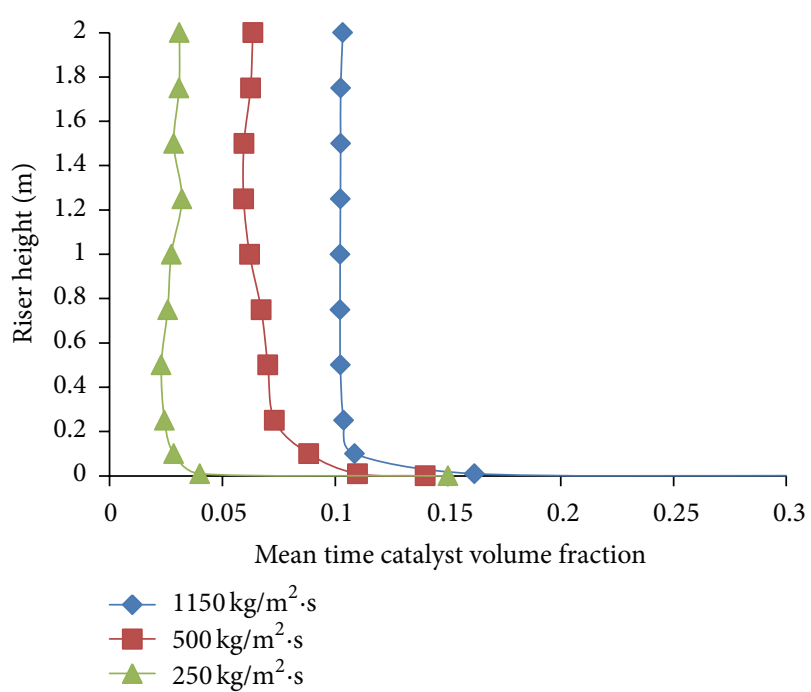

FigURE 14: Effect of inlet catalyst flux on catalyst volume fraction axial profile at different catalyst fluxes for $6.78 \mathrm{~kg} / \mathrm{m}^{2} \cdot \mathrm{s}$ of gas flow.

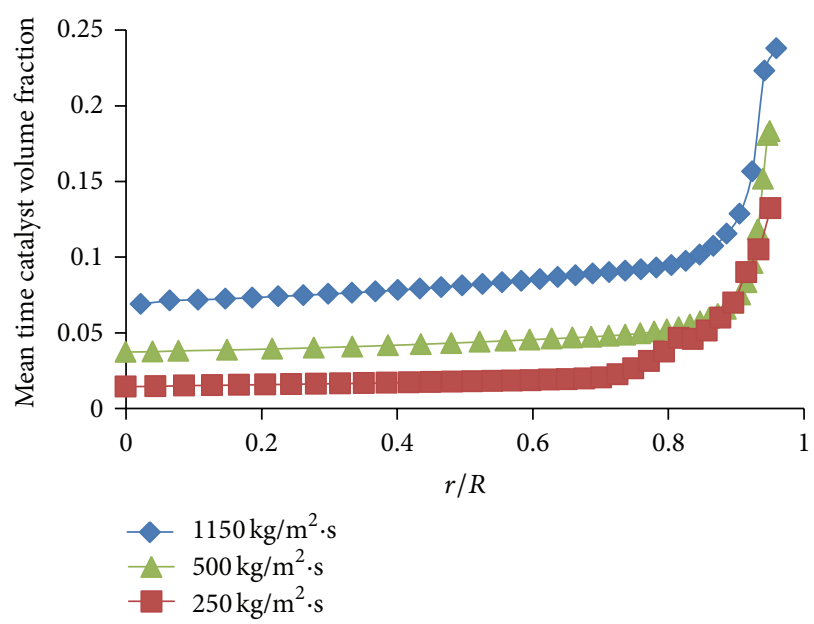

FIGURE 15: Effect of inlet catalyst flux on catalyst volume fraction radial profile at different catalyst fluxes for $6.78 \mathrm{~kg} / \mathrm{m}^{2} \cdot \mathrm{s}$ of gas flow at $1 \mathrm{~m}$ of the riser height.

in consideration while determining the optimum mixing in both directions, radial and axial.

\section{Conclusion}

It can be concluded that for optimum reactor yield, the CFBSR should be operated under DSU regime with a catalyst of Geldart's "A" type under high flux exceeding $\sim 500 \mathrm{Kg} / \mathrm{m}^{2} \cdot \mathrm{s}$ for the studied flow conditions. The overall catalyst mixing in the reactor is highly dependent on the catalyst flux inside the reactor at such high loadings. It was found that increasing the catalyst flux leads to two competing effects in the axial and radial mixing qualities, which determines the optimum catalyst flux values for the different gas flow conditions. As for the effect of inlet catalyst concentration on the reactor performance, it still needs further study at 
reactive conditions, as opposed to the cold flow runs in this publication, to set its optimum range. These catalyst rates and conditions are for a gas flux of $6.78 \mathrm{Kg} / \mathrm{m}^{2} \cdot \mathrm{s}$ operating at 5 atma and $923 \mathrm{~K}$, favoring the shift of the steam reforming equilibrium reaction to products side. The results from this study set the operating ranges for the reactive flow study to be conducted next.

\section{Notation}

$C_{D}:$ Drag coefficient

D: Diffusivity, $\mathrm{m}^{2} / \mathrm{s}$

$d_{s}$ : Diameter of the solid-phase particles, $m$

$F$ : Interphase momentum exchange term

$h$ : Specific enthalpy, $\mathrm{J} / \mathrm{kg}$

$\mathrm{K}$ : Interphase exchange coefficient

$k$ : Thermal conductivity

$K$ : $\quad$ Turbulent kinetic energy

$\mathrm{Nu}$ : Dimensionless Nusselt number

$T$ : $\quad$ Phase temperature

$k_{\Theta s}:$ Diffusion coefficient

$P$ : $\quad$ Pressure, $\mathrm{Pa}$

$Q_{p Q}$ : Intensity of heat exchange between two phases

$\underline{v}$ : Velocity vector, $\mathrm{m} / \mathrm{s}$

$\bar{v}_{r, s}:$ Terminal velocity of the solid phase, $\mathrm{m} / \mathrm{s}$

$x$ : $\quad$ Mass fraction.

\section{Greek Letters}

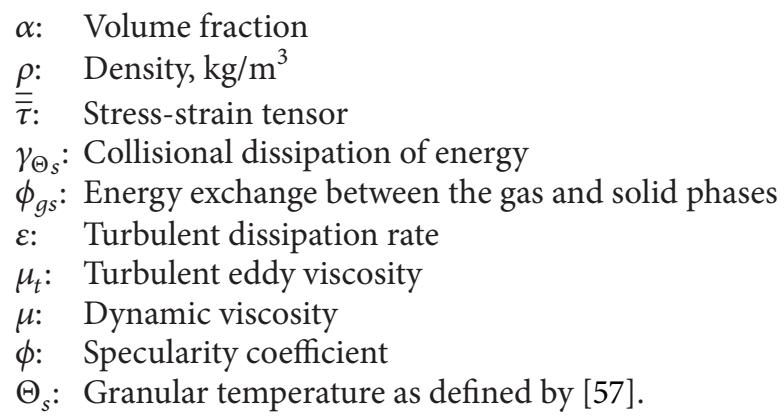

\section{Subscripts}

$$
\begin{aligned}
& \text { g: Gas } \\
& \text { p: Particle } \\
& \text { q: Phase } q \text {, either gas or solid } \\
& \text { s: Solid. }
\end{aligned}
$$

\section{Conflict of Interests}

The authors declare no competing financial interest regarding the publication of this paper.

\section{Acknowledgment}

The authors wish to acknowledge U.S.-Egypt Science and Technology Joint Fund for the financial support of this work, and Professor Dr. S. Elnashaie for the initiation of this research project and for his valuable discussions and contributions.

\section{References}

[1] V. A. Goltsov and T. N. Veziroglu, "A step on the road to hydrogen civilization," International Journal of Hydrogen Energy, vol. 27, no. 7-8, pp. 719-723, 2002.

[2] L. F. Brown, "A comparative study of fuels for on-board hydrogen production for fuel-cell-powered automobiles," International Journal of Hydrogen Energy, vol. 26, no. 4, pp. 381-397, 2001.

[3] M. V. Twigg, Catalyst Handbook, Wolfe, London, UK, 2nd edition, 1989.

[4] T. S. Christensen, "Adiabatic prereforming of hydrocarbons-an important step in syngas production," Applied Catalysis A, vol. 138, no. 2, pp. 285-309, 1996.

[5] D. Wang, S. Czernik, D. Montané, M. Mann, and E. Chornet, "Biomass to hydrogen via fast pyrolysis and catalytic steam reforming of the pyrolysis oil or its fractions," Industrial and Engineering Chemistry Research, vol. 36, no. 5, pp. 1507-1518, 1997.

[6] S. Czernik, R. French, C. Feik, E. Chornet, C. Gregoire-Padró, and F. Lau, "Production of hydrogen from biomass by pyrolysis/ steam reforming," Advances in Hydrogen Energy, pp. 87-91, 2000.

[7] J. R. Grace, A. S. Issangya, D. Bai, H. Bi, and J. Zhu, "Situating the high-density circulating fluidized bed," AIChE Journal, vol. 45, no. 10, pp. 2108-2116, 1999.

[8] Z. Chen, Y. Yan, and S. S. E. H. Elnashaie, "Novel circulating fast fluidized-bed membrane reformer for efficient production of hydrogen from steam reforming of methane," Chemical Engineering Science, vol. 58, no. 19, pp. 4335-4349, 2003.

[9] A. M. AlMuttahar, CFD modeling of the hydrodynamics of circulating fluidised bed riser [Ph.D. thesis], University of Britich Columbia, Vancouver, Canada, 2006.

[10] J. R. Grace, "Contacting modes and behavior classification of gas-solid and other two-phase suspensions," Canadian Journal of Chemical Engineering, vol. 64, no. 3, pp. 353-363, 1986.

[11] S. W. Kim, G. Kirbas, H. Bi, C. J. Lim, and J. R. Grace, "Flow behavior and regime transition in a high-density circulating fluidized bed riser," Chemical Engineering Science, vol. 59, no. 18, pp. 3955-3963, 2004.

[12] R. Kumar and K. M. Pandey, "CFD analysis of circulating fluidized bed combustion," Engineering Science and Technology, vol. 2, no. 1, pp. 163-174, 2012.

[13] A. Almuttahar and F. Taghipour, "Computational fluid dynamics of high density circulating fluidized bed riser: study of modeling parameters," Powder Technology, vol. 185, no. 1, pp. 1123,2008 .

[14] J. Bellan and D. Lathouwers, "Modeling of dense gas-solid reactive mixtures applied to biomass pyrolysis in a fluidized bed," International Journal of Multiphase Flow, vol. 27, no. 12, pp. 2155-2187, 2001.

[15] B. Wang, T. Li, Q. Sun, W. Ying, and D. Fang, "Solid concentration in circulating fluidized bed reactor for the MTO process," International Journal of Chemical and Biological Engineering, vol. 3, no. 2, p. 90, 2010.

[16] T. Boyd, C. Lim, J. Grace, and A. Adris, "Cold modelling of an internally circulating fluidized bed membrane reactor," in 
Proceedings of the 12th International Conference on FluidizationNew Horizons in Fluidization Engineering, 2007.

[17] M. Lim, S. Pang, and J. Nijdam, "Investigation of solids circulation in a cold model of a circulating fluidized bed," Powder Technology, vol. 226, pp. 57-67, 2012.

[18] G. Iaquaniello, A. Borruto, E. Lollobattista, G. Narducci, and D. Katsir, "Hydrogen palladium selective membranes: an economic prespective," in Membrane Reactors for Hydrogen Production Processes, chapter 3, Springer, New York, NY, USA, 2011.

[19] Z. Li, "Robust low-cost water-gas-shift membrane reactor for high-purity hydrogen production from coal-derived syngas," DOE Hydrogen Program, 2005.

[20] S. Deshmukh, S. Heinrich, L. Mörl, M. van Sint Annaland, and J. A. M. Kuipers, "Membrane assisted fluidized bed reactors: potentials and hurdles," Chemical Engineering Science, vol. 62, no. 1-2, pp. 416-436, 2007.

[21] M. M. Mousa, S. K. Fateen, and E. A. Ibrahim, "Hydrodynamic characteristics of a novel circulating fluidized bed steam reformer operating in the fast fluidization regime," International Journal of Chemical Reactor Engineering, vol. 9, p. A104, 2011.

[22] Z. Chen, Y. Yan, and S. Elnashaie, "Modeling and optimization of a novel membrane reformer for higher hydrocarbons," AIChE Journal, vol. 49, no. 5, pp. 1250-1265, 2003.

[23] K. S. Lim, J. X. Zhu, and J. R. Grace, "Hydrodynamics of gassolid fluidization," International Journal of Multiphase Flow, vol. 21, pp. 141-193, 1995.

[24] T. Van den Moortel, E. Azario, R. Santini, and L. Tadrist, "Experimental analysis of the gas-particle flow in a circulating fluidized bed using a phase Doppler particle analyzer," Chemical Engineering Science, vol. 53, no. 10, pp. 1883-1899, 1998.

[25] M. Van de Velden, J. Baeyens, and K. Smolders, "Solids mixing in the riser of a circulating fluidized bed," Chemical Engineering Science, vol. 62, no. 8, pp. 2139-2153, 2007.

[26] H. Zhu and J. Zhu, "Characterization of fluidization behavior in the bottom region of CFB risers," Chemical Engineering Journal, vol. 141, no. 1-3, pp. 169-179, 2008.

[27] D. Geldart, "Types of gas fluidization," Powder Technology, vol. 7, no. 5, pp. 285-292, 1973.

[28] Z. Chen, Y. Yan, and S. Elnashaie, "Hydrogen production and carbon formation during the steam reformer of heptane in a novel circulating fluidized bed membrane reformer," Industrial and Engineering Chemistry Research, vol. 43, no. 6, pp. 13231333, 2004.

[29] D. Gidaspow, R. Bezburuah, and J. Ding, "Hydrodynamics of circulating fluidized beds, kinetic theory approach," in Proceedings of the 7th Engineering Foundation Conference on Fluidization, Fluidization VII, 1992.

[30] C. Y. Wen and Y. H. Yu, "Mechanics of fluidization," Chemical Engineering Progress Symposium Series, vol. 62, 1966.

[31] M. Syamlal and T. J. O. 'Brien, "Computer simulation of bubbles in a fluidized bed," AIChE Symposium Series, 1989.

[32] H. Arastoopour, P. Pakdel, and M. Adewumi, "Hydrodynamic analysis of dilute gas-solids flow in a vertical pipe," Powder Technology, vol. 62, no. 2, pp. 163-170, 1990.

[33] C. Lun and S. B. Savage, "The effects of an impact velocity dependent coefficient of restitution on stresses developed by sheared granular materials," Acta Mechanica, vol. 63, no. 1-4, pp. 15-44, 1986.

[34] S. Ogawa, A. Umemura, and N. Oshima, "On the equations of fully fluidized granular materials," Zeitschrift für angewandte Mathematik und Physik ZAMP, vol. 31, no. 4, pp. 483-493, 1980.
[35] J. L. Sinclair and R. Jackson, "Gas-particle flow in a vertical pipe with particle-particle interactions," AIChE Journal, vol. 35, no. 9, pp. 1473-1486, 1989.

[36] C. M. Hrenya and J. L. Sinclair, "Effects of particle-phase turbulence in gas-solid flows," AIChE Journal, vol. 43, no. 4, pp. 853-869, 1997.

[37] J. J. Nieuwland, M. Van Sint Annaland, J. A. M. Kuipers, and W. P. M. Van Swaaij, "Hydrodynamic modeling of gas/particle flows in riser reactors," AIChE Journal, vol. 42, no. 6, pp. 15691582, 1996.

[38] A. Almuttahar and F. Taghipour, "Computational fluid dynamics of high density circulating fluidized bed riser: study of modeling parameters," Powder Technology, vol. 185, no. 1, pp. 1123, 2008.

[39] E. J. Bolio, J. A. Yasuna, and J. L. Sinclair, "Dilute turbulent gassolid flow in risers with particle-particle interactions," AIChE Journal, vol. 41, no. 6, pp. 1375-1388, 1995.

[40] D. J. Patil, M. van Sint Annaland, and J. Kuipers, "Modeling of turbulent gas-particle flows in risers: influence of turbulence modulation on the radial solids segregation," in Proceedings of the 8th International Conference on Circulating Fluidized Beds, Hangzhou, China, 2005.

[41] S. Benyahia, H. Arastoopour, T. M. Knowlton, and H. Massah, "Simulation of particles and gas flow behavior in the riser section of a circulating fluidized bed using the kinetic theory approach for the particulate phase," Powder Technology, vol. 112, no. 1-2, pp. 24-33, 2000.

[42] L. Huilin and D. Gidaspow, "Hydrodynamics of binary fluidization in a riser: CFD simulation using two granular temperatures," Chemical Engineering Science, vol. 58, no. 16, pp. 37773792, 2003.

[43] V. Jiradilok, D. Gidaspow, S. Damronglerd, W. J. Koves, and R. Mostofi, "Kinetic theory based CFD simulation of turbulent fluidization of FCC particles in a riser," Chemical Engineering Science, vol. 61, no. 17, pp. 5544-5559, 2006.

[44] H. Zhou, G. Flamant, and D. Gauthier, "Modeling of the turbulent gas-particle flow structure in a two-dimensional circulating fluidized bed riser," Chemical Engineering Science, vol. 62, no. 1-2, pp. 269-280, 2007.

[45] J. A. Pita and S. Sundaresan, "Developing flow of a gas-particle," AIChE Journal, vol. 39, no. 4, pp. 541-552, 1993.

[46] M. Tartan, D. Gidaspow, R. Mostofi, and Y. Shin, Computational and Experimental Modeling of Slurry Bubble Column Reactors: Measurement and Computation of Turbulence in Risers, US Department of Energy, Washington, DC, USA, 2001.

[47] V. Ranade, Computational Flow Modeling for Chemical Reactor Engineering, Process Systems Engineering, Academic Press, London, UK, 2002.

[48] P. C. Johnson and R. Jackson, "Frictional-collisional constitutive relations for granular materials, with application to plane shearing," Journal of Fluid Mechanics, vol. 176, pp. 67-93, 1987.

[49] V. Ranade, "Modeling of gas-solid flows in FCC riser: fully developed flow," in Proceedings of the 2nd International Conference on CFD in Minerals and Process Industries Melbourne, Melbourne, Australia, 1999.

[50] T. Li, J. Grace, and X. Bi, "Study of wall boundary condition in numerical simulations of bubbling fluidized beds," Powder Technology, vol. 203, no. 3, pp. 447-457, 2010.

[51] A. Neri and D. Gidaspow, "Riser hydrodynamics: simulation using kinetic theory," AIChE Journal, vol. 46, no. 1, pp. 52-67, 2000 . 
[52] M. Kruse and J. Werther, "2D gas and solids flow prediction in circulating fluidized beds based on suction probe and pressure profile measurements," Chemical Engineering and Processing, vol. 34, no. 3, pp. 185-203, 1995.

[53] C. H. Ibsen, T. Solberg, B. H. Hjertager, and F. Johnsson, "Laser Doppler anemometry measurements in a circulating fluidized bed of metal particles," Experimental Thermal and Fluid Science, vol. 26, no. 6-7, pp. 851-859, 2002.

[54] A. Issangya, J. Grace, D. Bai, and J. Zhu, "Further measurements of flow dynamics in a high-density circulating fluidized bed riser," Powder Technology, vol. 111, no. 1-2, pp. 104-113, 2000.

[55] A. Passalcqua, CFD simulation of gas-solid flows [Ph.D. thesis], Politecnico di Torino, Torino, Italy, 2006.

[56] S. Benyahia, H. Arastoopour, and T. M. Knowlton, "Twodimensional transient numerical simulation of solids and gas flow in the riser section of a circulating fluidized bed," Chemical Engineering Communications, vol. 189, no. 2, pp. 510-527, 2002.

[57] J. Ding and D. Gidaspow, "A bubbling fluidization model using kinetic theory of granular flow," AIChE Journal, vol. 36, no. 4, pp. 523-538, 1990. 

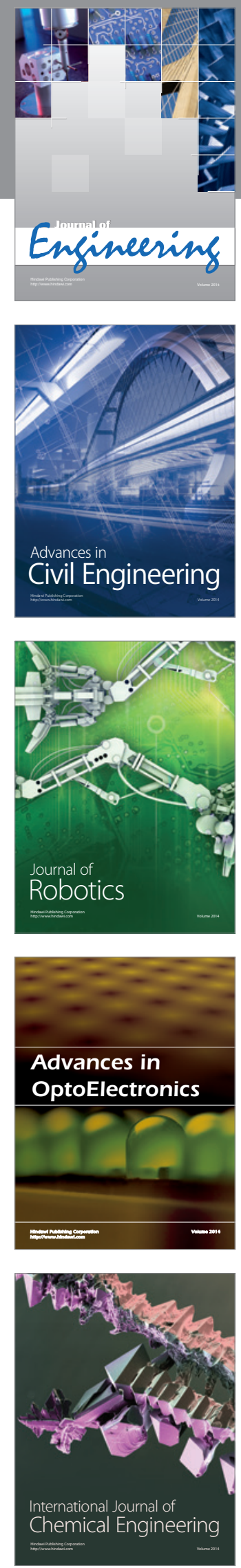

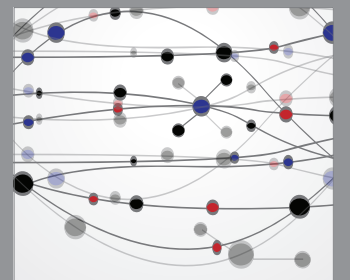

The Scientific World Journal
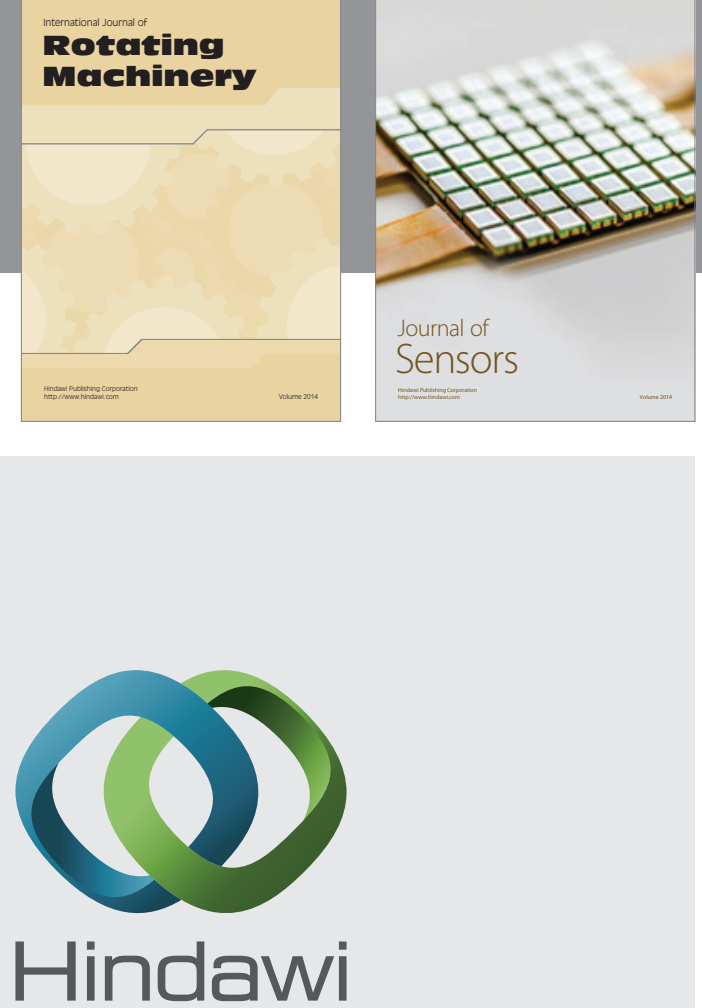

Submit your manuscripts at http://www.hindawi.com
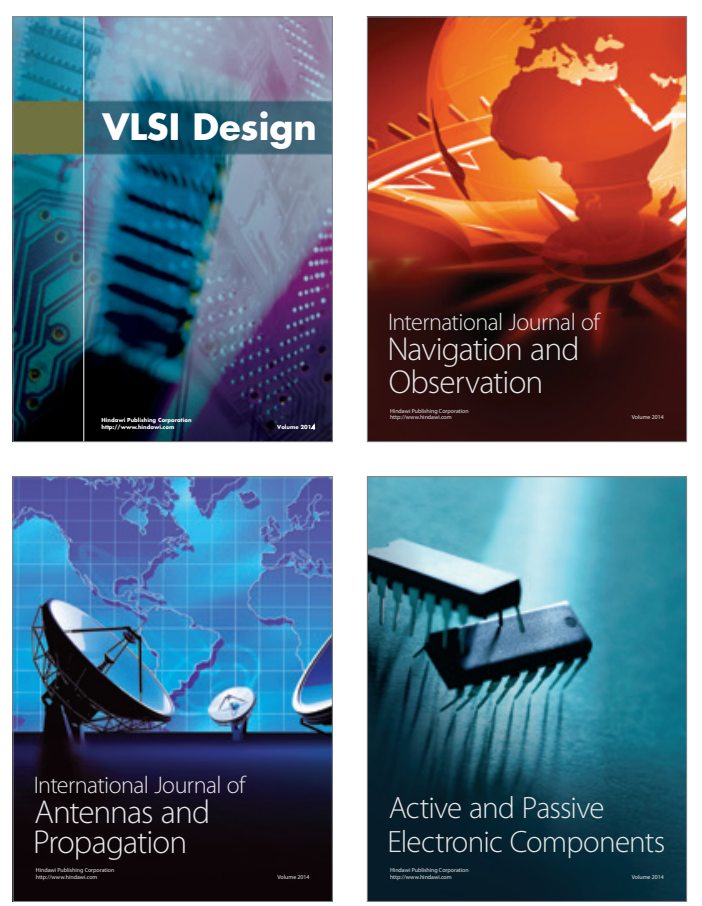
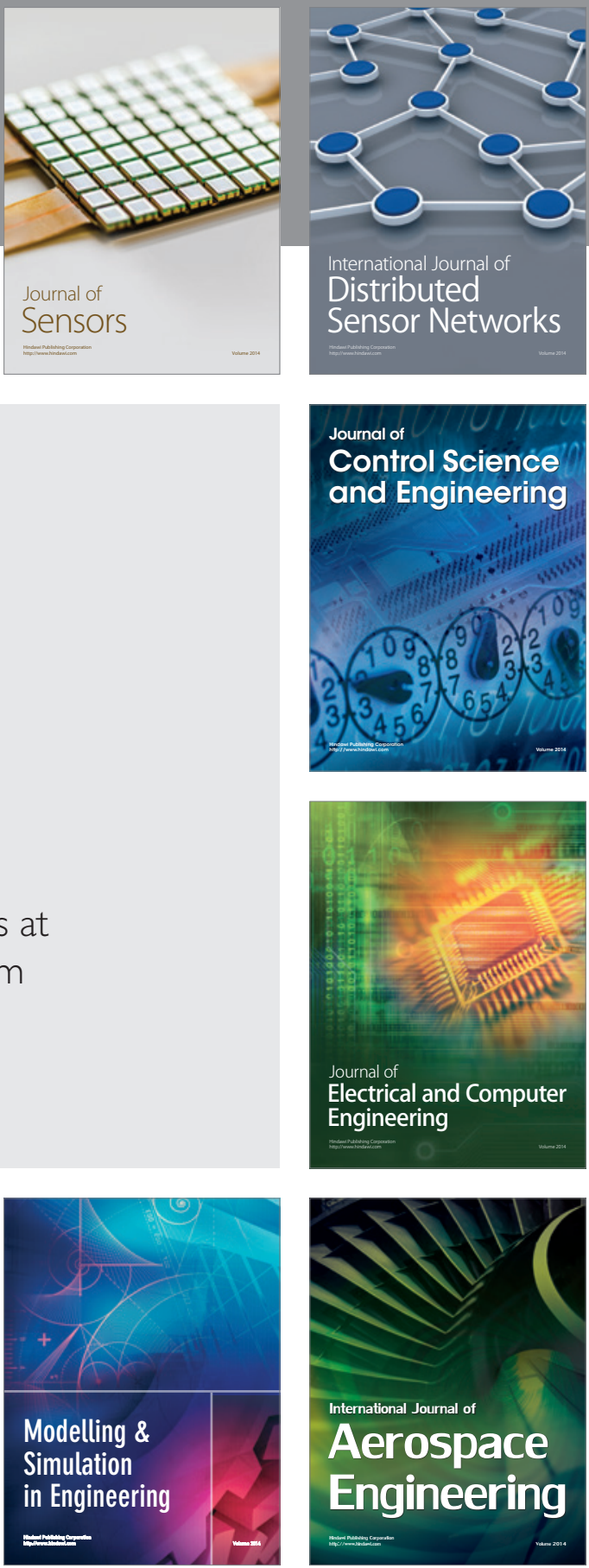

Journal of

Control Science

and Engineering
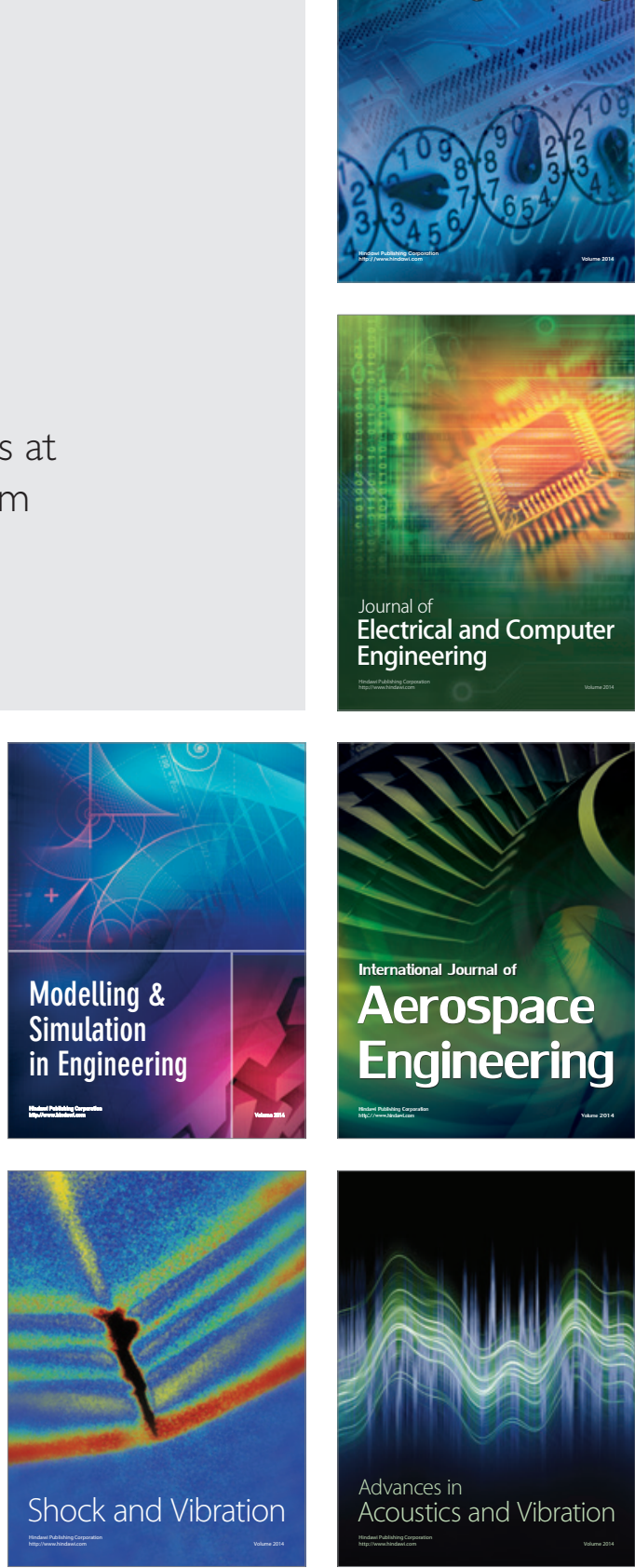